\title{
Strategies of Knowledge Pricing and the Impact on Firms' New Product Development Performance
}

\author{
Chuanrong $\mathrm{Wu}^{1 *}$, Ning Tan ${ }^{1}$, Zhi Lu ${ }^{2}$, Xiaoming Yang ${ }^{3}$, and Mark E. McMurtrey ${ }^{4}$ \\ ${ }^{1}$ School of Economy and Management, Changsha University of Science \& Technology \\ Changsha, HN 410114 China \\ [e-mail: wuchuanrong01@126.com] \\ ${ }^{2}$ Peter B. Gustavson School of Business, University of Victoria \\ Victoria, BC V8P5C2 Canada \\ [e-mail: zhilu@uvic.ca] \\ ${ }^{3}$ College of Business Administration, University of Nebraska at Omaha \\ Omaha, NE 68182 USA \\ [e-mail: xyang2@unomaha.edu] \\ ${ }^{4}$ College of Business, University of Central Arkansas \\ Conway, AR 72035 USA \\ [e-mail: markmc@uca.edu] \\ ${ }^{*}$ Corresponding author: Chuanrong Wu
}

Received March 2, 2021; revised May 1, 2021; accepted May 16, 2021;

published August 31, 2021

\begin{abstract}
The economics of big data knowledge, especially cloud computing and statistical data of consumer preferences, has attracted increasing academic and industry practitioners' attention. Firms nowadays require purchasing not only external private patent knowledge from other firms, but also proprietary big data knowledge to support their new product development. Extant research investigates pricing strategies of external private patent knowledge and proprietary big data knowledge separately. Yet, a comprehensive investigation of pricing strategies of these two types of knowledge is in pressing need. This research constructs an overarching pricing model of external private patent knowledge and proprietary big data knowledge through the lens of firm profitability as a knowledge transaction recipient. The proposed model can help those firms who purchase external knowledge choose the optimal knowledge structure and pricing strategies of two types of knowledge, and provide theoretical and methodological guidance for knowledge transaction recipient firms to negotiate with knowledge providers.
\end{abstract}

Keywords: Knowledge transaction, two-part tariff pricing,lump-sum pricing, royalty pricing, subscription pricing, pay-per-use pricing

This research was supported by the National Natural Science Foundation of China, grant number 71704016, the Key Scientific Research Fund of Hunan Provincial Education Department of China, grant number 19A006, and the Enterprise Strategic Management and Investment Decision Research Base of Hunan Province (19qyzd03). 


\section{Introduction}

W ith the unprecedented fast progress of the big data era, mining insights from big data and managing the corresponding knowledge are key factors for firms to enhance their competitive advantage [1-4]. In addition to private patent knowledge that firms could develop internally or purchase externally from other organizations, proprietary big data knowledge has become an essential type of knowledge required for firms' new product development. With big data knowledge, firms can understand customers' preferences, predict their demands, and develop new products to meet those needs by leveraging product evaluation and trial data from product transaction platforms, blogs, Twitter, WeChat, and other social networks [5-9]. Given big data includes not only structured data but also semi-structured or even unstructured data that present in a variety of sources, there are a range of data analysis firms, consulting firms, or cloud computing firms that glean big data knowledge from vast amounts of data sources using text mining, quantitative prediction models, Knowledge Discovery in Data (KDD), data mining, and visualization and provider proprietary big data knowledge to those firms in need as knowledge transaction recipients. These proprietary big data knowledge providers have become new entities of knowledge transactions $[10,11]$. Consequently, in this big data environment, proprietary big data knowledge has become an integral part that firms need to purchase to develop their new products, in addition to the private patent knowledge they accumulate within their firms internally or acquire from other organizations externally. Accordingly, the activities of knowledge transactions have become more complicated than before.

Scholars have conducted a lot of research from the perspective of pricing strategies for private knowledge, especially for private intellectual property licensing [12-14]. Arrow (1972) introduces the concept of patent licensing. He also contends that patent holders would charge fixed fees or royalty payments for using the new patent as a return for their investment in research and development (R\&D) [15]. Vishwasrao (2007) finds that the private knowledge providers prefer to use the royalties pricing method in a patent licensing transaction when the sales of a new product based on this patent are relatively high; in contrast, fluctuant product sales and higher profitability are conducive to the fixed fee pricing method in patent licensing transaction [16]. Recently, some scholars reveal that the two-part tariff pricing method, including a fixed fee and an optimal per-unit royalty, positively impacts the relatively significant patent innovations of private knowledge providers [17, 18].

Extant research has also examined different pricing strategies for proprietary big data knowledge. It is suggested that the most popular pricing strategies for proprietary big data knowledge transactions are subscription pricing, pay-per-use pricing, and two-part tariff pricing [19-24]. Although prior research has demonstrated the importance of proprietary big data knowledge and paid attention to its pricing strategies, these studies mainly focus on the pricing methods of a single type of knowledge and lack a comprehensive examination of both proprietary big data knowledge and private patent knowledge. This research posits that although proprietary big data knowledge characteristics are different from that of private patent knowledge, the basic pricing methods are similar. Therefore, the pricing methods of these two types of knowledge and their impact on firms' new product development performance shall be investigated in a comprehensive manner. Therefore, this research constructs a pricing model of proprietary big data knowledge and private patent knowledge from a knowledge transaction recipients' standpoint. This model helps knowledge transaction recipients to optimize their knowledge structure and pricing schemes of two types of 
knowledge. Meanwhile, this research's findings provide theoretical and methodological guidance for knowledge transaction recipient firms to negotiate with knowledge providers.

The paper first commences with current pricing methods and challenges faced when conducting knowledge transactions in the big data era. Then, the pricing framework and model hypotheses are proposed in Section 2. Section 3 presents a pricing strategies selection model of two types of knowledge, while Section 4 compares the experimental results of three price strategies and discusses its implication. Section 5 contains conclusions and provides directions for future work.

\section{Pricing Framework and Model Hypotheses}

\subsection{Pricing Framework for Two Types of Knowledge Transaction}

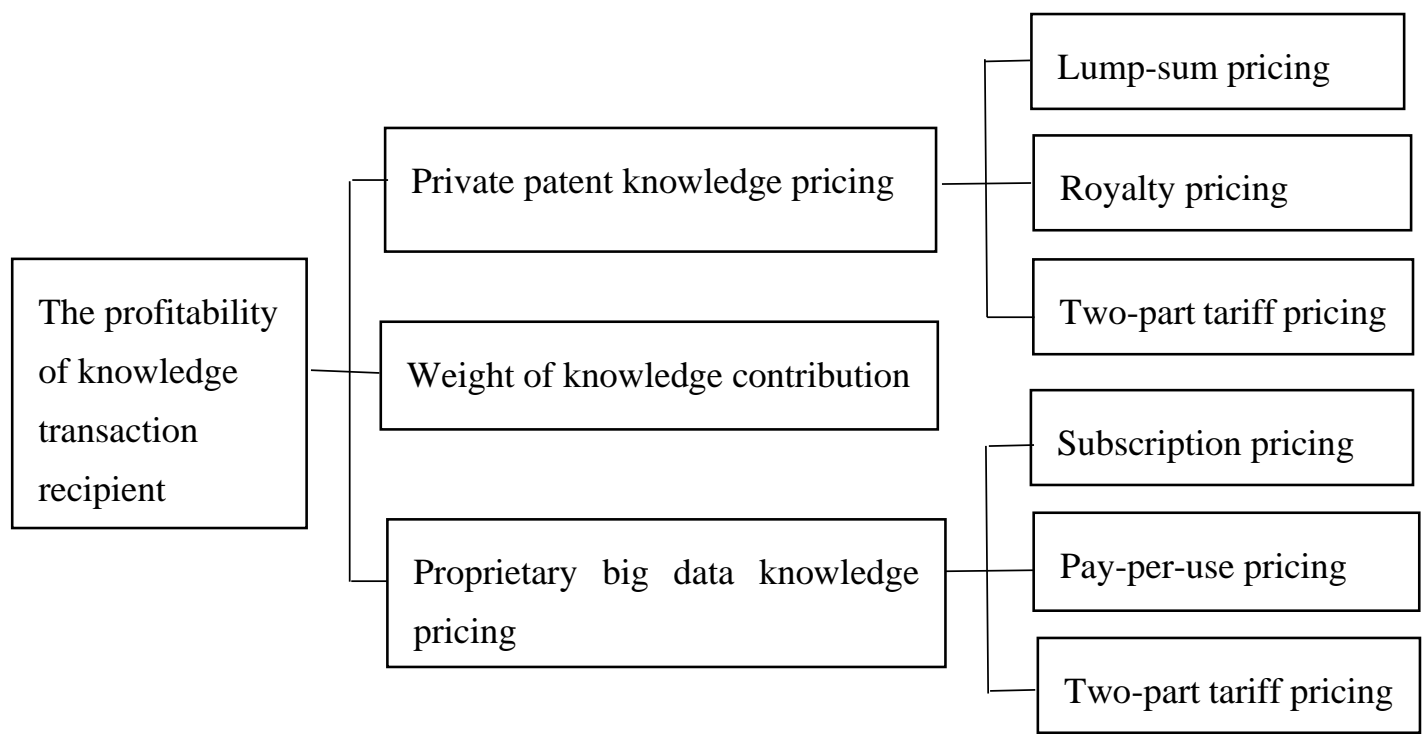

Fig. 1. Pricing framework for two types of knowledge transaction

Suppose a new product development of a firm needs both private patent knowledge and proprietary big data knowledge. Hence, the knowledge pricing in knowledge transactions includes two aspects: private patent knowledge pricing and proprietary big data knowledge pricing. Knowledge transaction recipient firms could access private patent knowledge by paying a fixed one-time fee, that is, a lump-sum fee, to purchase the full license rights. They can also extract profits through a per-unit royalty on production. Private patent knowledge providers sometimes also employ a two-part tariff pricing scheme which consists of a fixed fee plus a per-unit royalty payment. Therefore, there are three pricing schemes for private patent knowledge transactions: lump-sum pricing, royalty pricing, and two-part tariff pricing. The pricing schemes of proprietary big data knowledge transactions also include three types of strategies: subscription pricing, pay-per-use pricing, and two-part tariff pricing [23]. With subscription pricing, knowledge transaction recipient firms pay a fixed fee on a recurring basis to access the proprietary big data knowledge's license rights as an online service. With payper-use pricing, knowledge transaction recipients only have to pay according to the percentage of knowledge they use. Also, two-part tariff pricing has nowadays become a popular pricing strategy among proprietary big data knowledge providers. With two-part tariff pricing, 
proprietary big data knowledge providers charge the knowledge transaction recipients an optimal per-transaction fee plus a fixed fee (usually registration fee of the platform) [25].

Knowledge transaction can be viewed as a process of knowledge transfer [26]. Thus, the decision-making principle and method of knowledge transfer can be employed for the selection of knowledge structure and the pricing strategies of knowledge transaction recipients. In light of this, the knowledge transaction recipient's profitability can be calculated by new product development performance after knowledge transaction. To select optimal knowledge structure and pricing strategies for knowledge transaction, a knowledge pricing decision model can be set up by maximizing the expected profit of a knowledge transaction recipient, which needs to purchase both private patent knowledge and proprietary big data knowledge to develop a new product. The pricing framework of two types of knowledge transactions is depicted in Fig. 1.

\subsection{Model Hypotheses}

Hypothesis 1. $V_{i}$ is a firm that needs both private patent knowledge and big data knowledge to develop a new product. At time $T$ the firm $V_{i}$ buys one type of private patent knowledge from a private patent knowledge provider $V_{j}$ and one type of proprietary big data knowledge from an proprietary big data knowledge provider $B D_{k}$ simultaneously. $V_{i}$ merely produces one product, and it will take new product development immediately after knowledge transaction.

Hypothesis 2. $k_{11}$ is the part of fixed fee of private patent knowledge, $k_{12}$ is the per-unit royalty of private patent knowledge on production. $k_{21}$ is the registration fee of big data knowledge, $k_{22}$ is the price cap of each proprietary big data knowledge transaction, and $k_{11}, k_{12}, k_{21}, k_{22}$ are constants.

Hypothesis 3. $q_{1}$ represents the production of new product after private and proprietary big data knowledge transaction. $q_{2}\left(0 \leq q_{2} \leq 1\right)$ denotes the usage ratio of proprietary big data knowledge. $q_{2}=1$ represents $V_{i}$ will purchase full access of exploitation for the proprietary big data knowledge in this knowledge transaction.

Hypothesis 4. The total transaction cost of two types of knowledge $K$ includes the fixed transaction cost $k_{f i x}$ and the variable transaction cost $k_{\mathrm{var}}$.

Hypothesis 5. $\omega_{1}, \omega_{2}$ are the weights of private patent knowledge contribution and proprietary big data knowledge contribution to the total update rate of external knowledge that $V_{i}$ purchases from $V_{j}$ and $B D_{k}$ for new product development $\left(0 \leq \omega_{1}, \omega_{2} \leq 1, \omega_{1}+\omega_{2}=1\right)$.

Hypothesis 6. $\beta_{1}\left(0<\beta_{1}<1\right)$ represents the update rate of private patent knowledge at the starting point when $V_{i}$ only purchases private patent knowledge from $V_{j}$. Similarly, $\beta_{2}\left(0<\beta_{2}<1\right)$ is the update rate of proprietary big data knowledge at the starting point when $V_{i}$ only purchases proprietary big data knowledge from $B D_{k}$, and $\beta(0<\beta<1)$ is the 
total update rate of external knowledge at the starting point brought by these two types of knowledge.

Hypothesis 7. The new private patent knowledge can increase the market share by $\rho_{1}\left(0<\theta_{1}<\rho_{1}<1\right)$ in first $L_{2}$ periods right after private patent knowledge transaction. The new proprietary big data knowledge can make market share grow $\rho_{2}\left(0<\theta_{1}<\rho_{2}<1\right)$ in first $L_{2}$ periods right after the proprietary big data knowledge transaction. $\rho\left(0<\theta_{1}<\rho<1\right)$ is the total growth rate of the market share of the new product in first $L_{2}$ periods brought by two types of knowledge transactions.

Hypothesis 8. $V_{i}$ conducts two types of knowledge transactions simultaneously at time period $T$, and develops new product immediately after the knowledge transaction. $\zeta(T)$ is the discounted expected profit (DEP) of $V_{i}$ before knowledge transaction and new product development, $\xi(T)$ is the DEP of $V_{i}$ after knowledge transactions and new product development, and $K(T)$ is the total cost of knowledge transactions. The total DEP $\psi(T)$ can be calculated by $\psi(T)=\zeta(T)+\xi(T)-K(T)$.

The model of this paper is a further research on knowledge transactions [24]. In order to verify the model and compare it with previous research findings, we follow Wu and Zeng (2009) in the same assumptions and variables [27]. These variables are as follows: $Q$ is the total product market volume; $p$ is the product price; $M C$ is the product marginal cost at the starting period; $\phi$ is the market share of the new product at the initiation stage, which first rises at a rate of $\theta_{1}\left(0<\theta_{1}<1\right)$ in time periods $L_{1}$ and then descends at a rate of $\theta(0<\theta<1)$ in other periods; the knowledge absorption capacity of $V_{i}$ is $\alpha(0<\alpha<1)$; the discount rate is $r$; the product life cycle is $N$, and $N$ should be recalculated after the two types of knowledge transactions.

\section{Decision Model of Pricing Strategies for Knowledge Transactions}

\subsection{Expected Profits before Two Types of Knowledge Transactions}

At the stage before knowledge transactions, $V_{i}$ produces a product with its original knowledge. With this background, sales revenue minus production costs, and discounted to the starting point, we can get the discounted expected profit (DEP) before two types of knowledge transactions, as shown in Equation (1). The detailed derivation process of Equation (1) can refer to the research results of Wu and Zeng (2009) [27]. 


$$
\zeta(T)=\left\{\begin{array}{lr}
p Q \phi \sum_{n=1}^{T}\left(1+\theta_{1}\right)^{n} r^{n}-Q \phi M C \sum_{n=1}^{T}\left(1+\theta_{1}\right)^{n} \alpha^{n} r^{n} & T \leq L_{1} \\
p Q \phi \sum_{n=1}^{L_{1}}\left(1+\theta_{1}\right)^{n} r^{n}-Q \phi M C \sum_{n=1}^{L_{1}}\left(1+\theta_{1}\right)^{n} \alpha^{n} r^{n}+p Q \phi\left(1+\theta_{1}\right)^{L_{1}} \sum_{n=L_{1}+1}^{T}(1-\theta)^{n-L_{1}} r^{n} \\
-Q \phi M C\left(1+\theta_{1}\right)^{L_{1}} \sum_{n=L_{1}+1}^{T}(1-\theta)^{n-L_{1}} \alpha^{n} r^{n} & T>L_{1}
\end{array}\right.
$$

\subsection{Expected Profit after Two Types of Knowledge Transaction}

We model a firm's pricing decision of knowledge transaction as a one-time irreversible pricing scheme selection decision. Hence, after time $T$, the firm completes knowledge transaction and produces new product with two types of new knowledge. According to hypotheses 3,5 , and $7, \rho, \rho_{1}$ and $\rho_{2}$ are the total market share growth rate, the market share growth rate in the first $L_{2}$ periods after $V_{i}$ only purchases private patent knowledge in knowledge transaction, and the market share growth rate in the first $L_{2}$ periods after $V_{i}$ merely purchases proprietary big data knowledge in knowledge transaction, respectively. Knowledge becomes more efficient over time, and the more efficient the type of knowledge the larger the values of $\rho, \rho_{1}$, and $\rho_{2}$. However, the efficiency level of proprietary big data knowledge is $q_{2} \rho_{2}$ in that $q_{2}$ is the percentage of proprietary big data knowledge transactions. Meanwhile, $\omega_{1}, \omega_{2}$ are the weights of private patent knowledge contribution and proprietary big data knowledge contribution to the total update rate of external new knowledge, which leads to the total market share growth rate $\rho$ as Equation (2).

$$
\rho=\omega_{1} \rho_{1}+\omega_{2} q_{2} \rho_{2} \quad\left(0 \leq q_{2} \leq 1\right)
$$

If $V_{i}$ takes knowledge transactions at time period $T$, the market share of the new product at time period $T$ is $\phi\left(1+\theta_{1}\right)^{T}$ when $T \leq L_{1}$, and $\phi\left(1+\theta_{1}\right)^{L_{1}}(1-\theta)^{T-L_{1}}$ when $T>L_{1}$. New private patent knowledge and proprietary big data knowledge begin to influence the market share of the product after adopting new knowledge. According to hypotheses 7, the product's market share first increases with a rate of $\rho$ in $L_{2}$ periods after knowledge transaction, and then falls at a rate of $\theta$. Therefore, if we denote the new product's the market share by $\lambda(n, T)$, then it can be obtained by Equation (3).

$$
\lambda(n, T)= \begin{cases}\phi\left(1+\theta_{1}\right)^{T}\left(1+\omega_{1} \rho_{1}+\omega_{2} q_{2} \rho_{2}\right)^{n} & n \leq L_{2}, T \leq L_{1} \\ \phi\left(1+\theta_{1}\right)^{L_{1}}(1-\theta)^{T-L_{1}}\left(1+\omega_{1} \rho_{1}+\omega_{2} q_{2} \rho_{2}\right)^{n} & n \leq L_{2}, T>L_{1} \\ \phi\left(1+\theta_{1}\right)^{T}\left(1+\omega_{1} \rho_{1}+\omega_{2} q_{2} \rho_{2}\right)^{n}(1-\theta)^{n-L_{2}} & n>L_{2}, T \leq L_{1} \\ \phi\left(1+\theta_{1}\right)^{L_{1}}(1-\theta)^{T-L_{1}}\left(1+\omega_{1} \rho_{1}+\omega_{2} q_{2} \rho_{2}\right)^{L_{2}}(1-\theta)^{n-L_{2}} & n>L_{2}, T>L_{1}\end{cases}
$$


$Q$ is defined as the total product market volume, $\lambda(n, T)$ is the market share of the new product in period $n$, then product sales are $Q \lambda(n, T)$. If all the products are sold, the production of the new product after knowledge transactions $q_{1}$ can be calculated by Equation (4).

$$
q_{1}=Q \lambda(n, T)= \begin{cases}Q \phi\left(1+\theta_{1}\right)^{T}\left(1+\omega_{1} \rho_{1}+\omega_{2} q_{2} \rho_{2}\right)^{n} & n \leq L_{2}, T \leq L_{1} \\ Q \phi\left(1+\theta_{1}\right)^{L_{1}}(1-\theta)^{T-L_{1}}\left(1+\omega_{1} \rho_{1}+\omega_{2} q_{2} \rho_{2}\right)^{n} & n \leq L_{2}, T>L_{1} \\ Q \phi\left(1+\theta_{1}\right)^{T}\left(1+\omega_{1} \rho_{1}+\omega_{2} q_{2} \rho_{2}\right)^{n}(1-\theta)^{n-L_{2}} & n>L_{2}, T \leq L_{1} \\ Q \phi\left(1+\theta_{1}\right)^{L_{1}}(1-\theta)^{T-L_{1}}\left(1+\omega_{1} \rho_{1}+\omega_{2} q_{2} \rho_{2}\right)^{L_{2}}(1-\theta)^{n-L_{2}} & n>L_{2}, T>L_{1}\end{cases}
$$

According to hypotheses 3,5 and $6, \beta, \beta_{1}$, and $\beta_{2}$ are the total update rate of external knowledge, the knowledge update rate brought by private patent knowledge, and the knowledge update rate brought by proprietary big data knowledge. Similarly, $\omega_{1}, \omega_{2}$ are the contribution weights of private patent knowledge and proprietary big data knowledge to the total external knowledge, and $q_{2}$ represents the usage ratio of the proprietary big data knowledge. Thus, $\beta$ can be defined by Equation (5).

$$
\beta=\omega_{1} \beta_{1}+\omega_{2} q_{2} \beta_{2} \quad\left(0 \leq q_{2} \leq 1\right)
$$

After two types of knowledge transactions at time period $T$, the new product's knowledge has been updated by the external knowledge update rate $\beta^{T}$. Knowledge becomes more efficient over time, and it can lead the marginal cost of the product at time period $T$ reduced to $M C \beta^{T}$. However, given not all knowledge can be absorbed by firms, the marginal cost of the product at time period $T$ will be reduced to $M C \beta^{T} \alpha^{n}$ when the knowledge absorption capacity of $V_{i}$ is $\alpha$. The total production cost in the time period $n$ after two types of knowledge transactions is equal to $Q \lambda(n, T) M C \beta^{T} \alpha^{n}$. Subtract total production cost from the sales revenue $p Q \lambda(n, T)$, and multiply $r^{T} r^{n}$ to discount the profits to the starting point, the DEP after two types of knowledge transactions can be expressed as Equation (6).

$$
\xi(T)=\sum_{n=1}^{N} p Q \lambda(n, T) r^{T} r^{n}-\sum_{n=1}^{N} Q \lambda(n, T) M C\left(\omega_{1} \beta_{1}+\omega_{2} q_{2} \beta_{2}\right)^{T} \alpha^{n} r^{T} r^{n}
$$

Replace $\lambda(n, T)$ in Equation (6) with Equation (3), the DEP after two types of knowledge transactions and new product development can be expressed as Equation (7). 


$$
\xi(T)= \begin{cases}p Q \phi\left(1+\theta_{1}\right)^{T} r^{T} \sum_{n=1}^{L_{2}}\left(1+\omega_{1} \rho_{1}+\omega_{2} q_{2} \rho_{2}\right)^{n} r^{n} \\ -M C Q \phi\left(1+\theta_{1}\right)^{T} r^{T}\left(\omega_{1} \beta_{1}+\omega_{2} q_{2} \beta_{2}\right)^{T} \sum_{n=1}^{L_{2}}\left(1+\omega_{1} \rho_{1}+\omega_{2} q_{2} \rho_{2}\right)^{n} \alpha^{n} r^{n} \\ +p Q \phi\left(1+\theta_{1}\right)^{T}\left(1+\omega_{1} \rho_{1}+\omega_{2} q_{2} \rho_{2}\right)^{L_{2}} r^{T} \sum_{n=L_{2}+1}^{N}(1-\theta)^{n-L_{2}} r^{n} \\ -M C Q \phi\left(1+\theta_{1}\right)^{T} r^{T}\left(\omega_{1} \beta_{1}+\omega_{2} q_{2} \beta_{2}\right)^{T}\left(1+\omega_{1} \rho_{1}+\omega_{2} q_{2} \rho_{2}\right)^{L_{2}} \sum_{n=L_{2}+1}^{N}(1-\theta)^{n-L_{2}} \alpha^{n} r^{n} & T \leq L_{1} \\ p Q \phi\left(1+\theta_{1}\right)^{L_{1}}(1-\theta)^{T-L_{1}} r^{T} \sum_{n=1}^{L_{2}}\left(1+\omega_{1} \rho_{1}+\omega_{2} q_{2} \rho_{2}\right)^{n} r^{n} & \\ -M C Q \phi\left(1+\theta_{1}\right)^{L_{1}}(1-\theta)^{T-L_{1}}\left(\omega_{1} \beta_{1}+\omega_{2} q_{2} \beta_{2}\right)^{T} r^{T} \sum_{n=1}^{L_{2}}\left(1+\omega_{1} \rho_{1}+\omega_{2} q_{2} \rho_{2}\right)^{n} \alpha^{n} r^{n} & \\ +p Q \phi\left(1+\theta_{1}\right)^{L_{1}}(1-\theta)^{T-L_{1}}\left(1+\omega_{1} \rho_{1}+\omega_{2} q_{2} \rho_{2}\right)^{L_{2}} r^{T} \sum_{n=L_{2}+1}^{N}(1-\theta)^{n-L_{2}} r^{n} & \\ -M C Q \phi\left(1+\theta_{1}\right)^{L_{1}}(1-\theta)^{T-L_{1}} r^{T}\left(\omega_{1} \beta_{1}+\omega_{2} q_{2} \beta_{2}\right)^{T}\left(1+\omega_{1} \rho_{1}+\omega_{2} q_{2} \rho_{2}\right)^{L_{2}} \sum_{n=L_{2}+1}^{N}(1-\theta)^{n-L_{2}} \alpha^{n} r^{n} & T>L_{1}\end{cases}
$$

\subsection{Cost of Two Types of Knowledge Transaction}

We have assumed in hypothesis 4 that the cost of two types of knowledge transaction $K$ consists of the fixed transaction cost $k_{\text {fix }}$ and the variable transaction cost $k_{\mathrm{var}}$. To be specific, the total fixed knowledge transaction cost $k_{\text {fix }}$ consists of the fixed fee of two types of knowledge. For private patent knowledge, the royalty payment is the fee that is charged through a per-unit royalty on the production of new product. It is variable cost. Then, the fixed cost of private patent knowledge in two-part tariff pricing strategy only includes the fixed fee for private patent knowledge, that is $k_{11}$. For proprietary big data knowledge, if the usage rate of big data knowledge in each transaction is determined, the price for the proprietary big data knowledge is a fixed value. Therefore, the fixed cost of proprietary big data knowledge in a two-part tariff pricing scheme includes not only a fixed registration fee of the platform but also the price of each proprietary big data knowledge transaction. From hypotheses 2 and 3, $k_{21}$ is the fixed registration fee of proprietary big data knowledge, $k_{22}$ is the price cap of each big data knowledge transaction, and $q_{2}\left(0 \leq q_{2} \leq 1\right)$ represents the amount of proprietary big data knowledge purchased by knowledge transaction recipient firm, so the total fixed knowledge transaction cost $k_{\text {fix }}$ is as Equation (8).

$$
k_{\text {fix }}=k_{11}+\left(k_{21}+k_{22} q_{2}\right) \quad\left(0 \leq q_{2} \leq 1\right)
$$

As already mentioned, the royalty payment is related to production; hence it is a variable cost. Furthermore, the total variable cost $k_{\text {var }}$ is also associated with the potential differences between original internal knowledge and external new knowledge. $k_{12}$ is per-unit royalty of private patent knowledge, and $q_{1}$ represents the production of the new product after knowledge transaction. Let $F$ be the coefficient of the work done to overcome the potential 
knowledge difference, the total variable cost of knowledge transaction can be expressed by Equation (9).

$$
k_{\mathrm{var}}=k_{12} q_{1}+F\left[\alpha^{T}-\left(\omega_{1} \beta_{1}+\omega_{2} q_{2} \beta_{2}\right)^{T}\right] \quad\left(q_{1} \geq 0,0 \leq q_{2} \leq 1\right)
$$

With total fixed cost plus variable cost, and then discount to the starting point, we can obtain the total knowledge transaction cost, which is shown in Equation (10).

$$
K(T)=\left[\left(k_{11}+k_{12} q_{1}\right)+\left(k_{21}+k_{22} q_{2}\right)+F\left[\alpha^{T}-\left(\omega_{1} \beta_{1}+\omega_{2} q_{2} \beta_{2}\right)^{T}\right]\right] r^{T}
$$

In Equation (10), the pricing strategy of private patent knowledge represents lump-sum pricing when $k_{11}>0$ and $k_{12}=0$, royalty pricing when $k_{11}=0$ and $k_{12}>0$, and two-part tariff pricing when $k_{11}>0$ and $k_{12}>0$. Similarly, the pricing strategy of proprietary big data knowledge is subscription pricing if $k_{22}=0$ and $k_{21}>0$. If we set $k_{21}=0, k_{22}>0$ and $0<q_{2}<1$, the pricing strategy of proprietary big data knowledge is pay-per-use pricing. If $k_{21}>0, k_{22}>0$ and $0<q_{2}<1$, the pricing strategy for purchasing proprietary big data knowledge is a two-part tariff pricing. Furthermore, if $k_{22}>0$ and $q_{2}=1$, we can view the pricing strategy of each proprietary big data knowledge transaction as subscription pricing.

Using Equation (4) to substitute the production of the new product $q_{1}$ in Equation (10), the total cost of knowledge transaction is denoted as Equation (11). In Equation (11), when $T \leq L_{1}$, knowledge transaction takes place before the decline of market share by using original knowledge, while the knowledge transaction occurs during the decline period of market share when $T>L_{1}$. Note that we follow the assumption that new knowledge will take effect on the product immediately after knowledge transaction, hence the newly acquired knowledge can make the market share grow at the rate of $\rho$ in the $L_{2}$ periods, and then decline at the rate of $\theta$.

$$
K(T)= \begin{cases}\left(k_{11}+k_{21}+k_{22} q_{2}\right) r^{T}+F r^{T}\left[\alpha^{T}-\left(\omega_{1} \beta_{1}+\omega_{2} q_{2} \beta_{2}\right)^{T}\right] & \\ +k_{12} Q \phi\left(1+\theta_{1}\right)^{T} r^{T} \sum_{n=1}^{L_{2}}\left(1+\omega_{1} \rho_{1}+\omega_{2} q_{2} \rho_{2}\right)^{n} r^{n} & \\ +k_{12} Q \phi\left(1+\theta_{1}\right)^{T}\left(1+\omega_{1} \rho_{1}+\omega_{2} q_{2} \rho_{2}\right)^{L_{2}} r^{T} \sum_{n=L_{2}+1}^{N}(1-\theta)^{n-L_{2}} r^{n} & T \leq L_{1} \\ \left(k_{11}+k_{21}+k_{22} q_{2}\right) r^{T}+F r^{T}\left[\alpha^{T}-\left(\omega_{1} \beta_{1}+\omega_{2} q_{2} \beta_{2}\right)^{T}\right] & \\ +k_{12} Q \phi\left(1+\theta_{1}\right)^{L_{1}}(1-\theta)^{T-L_{1}} r^{T} \sum_{n=1}^{L_{2}}\left(1+\omega_{1} \rho_{1}+\omega_{2} q_{2} \rho_{2}\right)^{n} r^{n} & \\ +k_{12} Q \phi\left(1+\theta_{1}\right)^{L_{1}}(1-\theta)^{T-L_{1}}\left(1+\omega_{1} \rho_{1}+\omega_{2} q_{2} \rho_{2}\right)^{L_{2}} r^{T} \sum_{n=L_{2}+1}^{N}(1-\theta)^{n-L_{2}} r^{n} & T>L_{1}\end{cases}
$$




\subsection{Total DEP of Two Type of Knowledge Transaction}

From the presumption, the future decisions of a firm that purchases private patent knowledge and proprietary big data knowledge is to optimize the knowledge structure and maximize the expected profit of its new product. Therefore, adding the current profits and the expected future profits after the knowledge transaction together, minus the total cost of the knowledge transaction, and then appropriately discounted, we can get the total DEP $\psi(T)$ as follows: add the current profits and the expected future profits after the knowledge transaction together, minus the total cost of the knowledge transaction, and then appropriately discounted. The maximum of total DEP is optimal for the firm to adopt new knowledge, then the total decision model of knowledge transaction is shown as Equation (12).

$$
\max \psi(T)=\max (\zeta(T)+\xi(T)-K(T))
$$

\section{Simulation and Results Analysis}

\subsection{Computation and Parameter Setting}

To derive the optimal knowledge structure, pricing strategies, and time for knowledge transaction, we turn to the differential equation (12) where $0 \leq T \leq N$, so that there is a maximum profit for a firm that will purchase two types of knowledge to develop a new product. Combining profit at time $T$ and the value-matching condition, we can arrive at the optimal knowledge structure and pricing strategies for knowledge transactions.

Due to the combined transaction of private patent knowledge and proprietary big data knowledge is a profound study of knowledge transfer under the big data environment [28-30], the values of those similar parameters in our model are set to the same as those parameters in prior research. Thus, these parameter values are as Table 1.

Table 1. Parameter values

\begin{tabular}{|c|c|c|c|c|c|c|c|c|c|c|c|c|c|c|c|}
\hline Parameter & $Q$ & $p$ & $M C$ & $L_{1}$ & $\theta$ & $\theta_{1}$ & $\phi$ & $\alpha$ & $L_{2}$ & $\rho_{1}$ & $\rho_{2}$ & $\beta_{1}$ & $\beta_{2}$ & $r$ & $F$ \\
\hline Value & 1000 & 60 & 40 & 3 & $3 \%$ & $3 \%$ & $8 \%$ & $95 \%$ & 5 & $6 \%$ & $8 \%$ & $88 \%$ & $88 \%$ & 0.9 & 1000 \\
\hline
\end{tabular}

\subsection{Simulation results}

\subsubsection{Validation of the model}

From Equation (7) and (11), when $k_{11}>0, k_{12}=0, \omega_{1}=1$, and $\omega_{2}=0$, it means that $V_{i}$ uses a lump-sum pricing scheme to buy one type of private patent knowledge. Similarly, when $k_{21}>0, k_{22}=0, \omega_{1}=0$, and $\omega_{2}=1$, it means that $V_{i}$ uses a subscription pricing scheme to buy one type of proprietary big data knowledge. In either situation, the price of knowledge is taken as a fixed value, which is similar to the presumption in the knowledge transfer model. Then, let $k_{11}=300$ and $k_{12}=0$ when $\omega_{1}=1$ and $\omega_{2}=0$, the total DEPs in Fig. 2 are the same as those in the previous knowledge transfer model of Wu et al. (2016) when the value of lump-sum fee is the same as the fixed cost of knowledge transfer, and the 
optimal timing for private patent knowledge transaction is $T=6$ [10]. Let $k_{21}=80$ and $k_{22}=0$ when $\omega_{1}=0$ and $\omega_{2}=1$, the simulation results in Fig. 2 are also the same as those in the previous knowledge transfer model of Wu et al. (2016) when the value of subscription fee for proprietary big data knowledge is the same as that of knowledge transfer fixed cost, and the optimal timing for proprietary big data knowledge transaction is $T=5$ [10]. Therefore, the model of this research is valid.

Let $k_{21}=0, k_{22}=80$ and $q_{2}=0.8$ when $\omega_{1}=0$ and $\omega_{2}=1$, it means that $V_{i}$ only purchases 80 percent of proprietary big data knowledge by using a pay-per-use pricing strategy. We can know from the results in Fig. 2 that the profits of $V_{i}$ in this pay-per-use pricing strategy are much higher than those when the price of proprietary big data knowledge is supposed to be a subscription fee. That is why, in the real business situation, many proprietary big data knowledge providers usually make some knowledge available for free when they adopt pay-per-use pricing, or waive platform registration fee when they adopt two-part tariff pricing so as to attract knowledge transaction recipients. At the same time, they rely on advertising revenues to compensate for the free knowledge they provide [23]. Thus, once again, the model in this paper is valid.

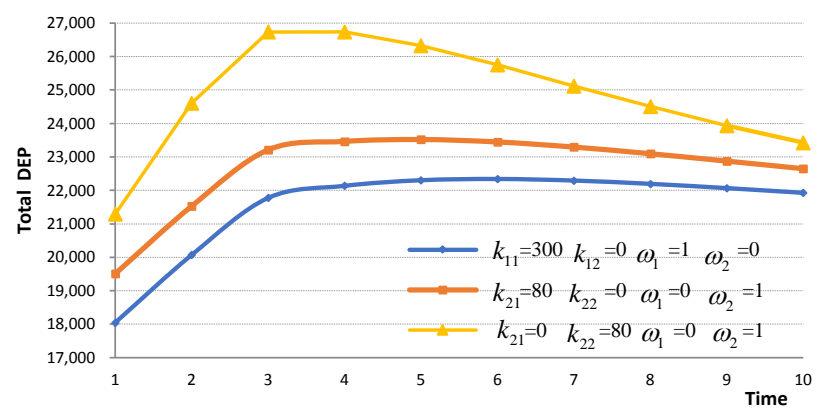

Fig. 2. Validation of the model.

\subsubsection{Simulation with pricing strategies of private patent knowledge}

In order to compare the profitability of knowledge purchaser with different private patent knowledge pricing schemes, let $k_{21}=0, k_{22}=0, \omega_{1}=1$ and $\omega_{2}=0$, it means that $V_{i}$ only purchases one type of private patent knowledge from a private patent knowledge provider. From Equation (10), the pricing scheme of private patent knowledge represents lump-sum pricing when $k_{11}>0$ and $k_{12}=0$, royalty pricing when $k_{11}=0$ and $k_{12}>0$, and two-part tariff pricing when $k_{11}>0$ and $k_{12}>0$. Adjust the values of $k_{11}$ and $k_{12}$, we can get the profitability of knowledge purchaser with different pricing schemes. Then, the pricing scheme of private patent knowledge is lump-sum pricing when $k_{12}=300$ and $k_{12}=0$. The pricing schemes of private patent knowledge are royalty pricing in different royalty rates when $k_{11}=0, k_{12}=0.6, k_{12}=1, k_{12}=2$, and $k_{12}=3$. Similarly, the pricing scheme of private patent knowledge is two-part tariff pricing when $k_{11}=50, k_{12}=0.5$ and $k_{12}=1$. Based on 
the simulation results in Table 2 and Fig. 3, the total DEPs when $k_{11}=0$ and $k_{12}=0.6$ are almost the same as those when $k_{12}=300$ and $k_{12}=0$, and the total DEPs when $k_{11}=50$ and $k_{12}=0.5$ are also roughly the same as those when $k_{12}=300$ and $k_{12}=0$. Therefore, a knowledge purchaser can predict and compare the profitability in different pricing schemes by adjusting the fixed fee and royalty rate when it negotiates with a private patent knowledge provider.

Adjust $k_{12}$ from 1 to 2 , and then from 2 to 3, which means that the private patent knowledge provider increases the royalty rate of private patent knowledge when $V_{i}$ only purchases private patent knowledge from it in a royalty pricing scheme. The simulation results in Table 2 and Fig. 3 show that the total DEPs decline and the optimal timing for private patent knowledge transaction switch from $T=6$ to $T=7$. The experimental results show that as the royalty rate of private patent knowledge increases, the cost of new product development increases, and the expected profit of the knowledge purchaser decreases. Knowledge purchasers will take private patent knowledge transactions more carefully, and the negotiation of private patent knowledge transactions contract will take a longer time [31].

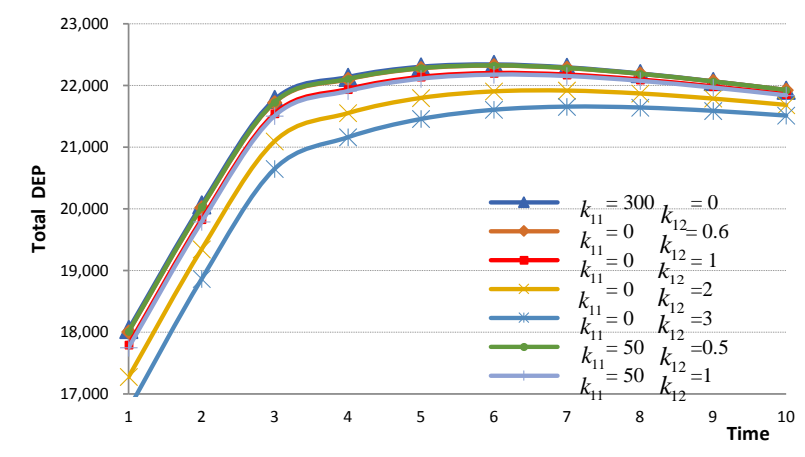

Fig. 3. Total DEPs in pricing strategies of private patent knowledge.

Table 2. Total DEP with pricing strategies of private patent knowledge

\begin{tabular}{|c|c|c|c|c|c|c|c|c|c|c|c|c|}
\hline Period & $\mathbf{1}$ & $\mathbf{2}$ & $\mathbf{3}$ & $\mathbf{4}$ & $\mathbf{5}$ & $\mathbf{6}$ & $\mathbf{7}$ & $\mathbf{8}$ & $\mathbf{9}$ & $\mathbf{1 0}$ & $k_{11}$ & $k_{12}$ \\
\hline DEP & $\mathbf{1 8 0 4 8}$ & $\mathbf{2 0 0 7 0}$ & $\mathbf{2 1 7 7 5}$ & $\mathbf{2 2 1 3 6}$ & $\mathbf{2 2 3 0 4}$ & $\mathbf{2 2 3 4 1}$ & $\mathbf{2 2 2 9 4}$ & $\mathbf{2 2 1 9 6}$ & $\mathbf{2 2 0 6 8}$ & $\mathbf{2 1 9 2 7}$ & $k_{11}=300$ & $k_{12}=0$ \\
\hline DEP & $\mathbf{1 8 0 0 5}$ & $\mathbf{2 0 0 2 3}$ & $\mathbf{2 1 7 2 5}$ & $\mathbf{2 2 0 9 9}$ & $\mathbf{2 2 2 7 6}$ & $\mathbf{2 2 3 2 2}$ & $\mathbf{2 2 2 8 2}$ & $\mathbf{2 2 1 8 8}$ & $\mathbf{2 2 0 6 5}$ & $\mathbf{2 1 9 2 8}$ & $k_{11}=0$ & $k_{12}=0.6$ \\
\hline DEP & 17797 & 19830 & 21546 & 21942 & 22140 & $\mathbf{2 2 2 0 3}$ & 22178 & 22098 & 21986 & 21858 & $k_{11}=0$ & $k_{12}=1$ \\
\hline DEP & 17276 & 19347 & 21098 & 21551 & 21798 & 21905 & $\mathbf{2 1 9 1 7}$ & 21871 & 21788 & 21685 & $k_{11}=0$ & $k_{12}=2$ \\
\hline DEP & 16754 & 18864 & 20650 & 21160 & 21457 & 21607 & $\mathbf{2 1 6 5 7}$ & 21643 & 21589 & 21512 & $k_{11}=0$ & $k_{12}=3$ \\
\hline DEP & $\mathbf{1 8 0 1 2}$ & $\mathbf{2 0 0 3 1}$ & $\mathbf{2 1 7 3 3}$ & $\mathbf{2 2 1 0 5}$ & $\mathbf{2 2 2 8 1}$ & $\mathbf{2 2 3 2 5}$ & $\mathbf{2 2 2 8 4}$ & $\mathbf{2 2 1 9 0}$ & $\mathbf{2 2 0 6 6}$ & $\mathbf{2 1 9 2 8}$ & $k_{11}=50$ & $k_{12}=0.5$ \\
\hline DEP & 17752 & 19790 & 21509 & 21909 & 22110 & $\mathbf{2 2 1 7 6}$ & 22154 & 22076 & 21967 & 21841 & $k_{11}=50$ & $k_{12}=1$ \\
\hline
\end{tabular}




\subsubsection{Simulation with pricing strategies of proprietary big data knowledge}

To compare the profitability of knowledge purchaser with different proprietary big data pricing schemes, we let $k_{11}=0, k_{12}=0, \omega_{1}=0, \omega_{2}=1$, and adjust the values of $k_{21}$, $k_{22}$, and $q_{2}$. We analyze a dynamic model with different big data pricing strategies. From Equation (10), when $k_{21}=80, k_{22}=0$, and $q_{2}=1$, it is assumed that $V_{i}$ purchases the proprietary big data knowledge with a subscription price of $k_{21}=80$. Let $k_{21}=0, k_{22}=80$, and adjust $q_{2}$ from 0.4 to 0.8 , it means that $V_{i}$ purchases the proprietary big data knowledge with a usage rate of $q_{2}=0.4$ and $q_{2}=0.8$ respectively in pay-per-use pricing strategies. Likewise, when $k_{21}=10$ and $k_{22}=70$, it is a two-part tariff pricing strategy, and the total price for proprietary big data knowledge is 80 at $q_{2}=1$ (When $q_{2}=1$, it means that whole right of exploitation for proprietary big data knowledge in per-transaction has been purchased by knowledge purchaser. For comparison purposes, the total price of proprietary big data knowledge with two-part tariff pricing should be equal to the subscription price and price cap of pay-per-use pricing). Adjust $q_{2}$ from 0.4 to 0.8 , the usage rate of per transaction in two-part pricing strategy is $q_{2}=0.4$ and $q_{2}=0.8$. From the simulation results in Table 3 , the total DEPs of pay-per-use pricing are only slightly higher than that of two-part tariff pricing, so we use two parts to show the simulation results. In Fig. 4, part (a) shows the total DEPs of subscription pricing and pay-per-use pricing, and part (b) shows the total DEPs of subscription pricing and two-part tariff pricing. It can be seen from the simulation results in Table 3 and Fig. 4 that the total DEPs are the smallest when $k_{21}=80, k_{22}=0$, and $q_{2}=1$. That is to say, the profitability of proprietary big data knowledge purchasers is the smallest in the subscription pricing scheme. Comparing the pay-per-use pricing with two-part tariff pricing in the same usage rate of proprietary big data knowledge, the total DEPs of knowledge purchaser in adopting pay-per-use pricing strategy are just slightly higher than those in adopting two-part tariff pricing strategy. This result shows that the registration fee has little effect on the profitability of proprietary big data knowledge providers, which is why proprietary big data knowledge providers are still not willing to charge registration fees of platform or even provide free knowledge, although the two-part tariff pricing is considered to be the most beneficial pricing strategy for proprietary big data knowledge providers [23]. This conclusion is consistent with the previous research, and the model is valid.

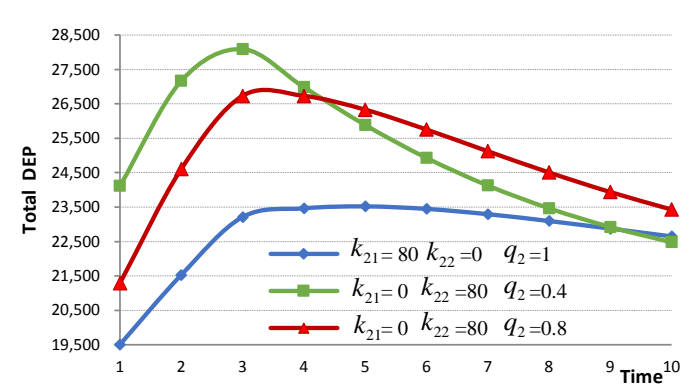

(a)

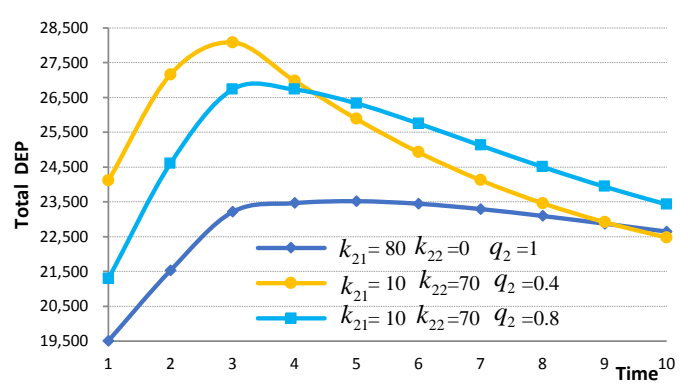

(b)

Fig. 4. Total DEPs in pricing strategies of the proprietary big data knowledge. 
Table 3. Total DEP with pricing strategies of the proprietary big data knowledge

\begin{tabular}{|c|c|c|c|c|c|c|c|c|c|c|c|c|c|}
\hline Period & $\mathbf{1}$ & $\mathbf{2}$ & $\mathbf{3}$ & $\mathbf{4}$ & $\mathbf{5}$ & $\mathbf{6}$ & $\mathbf{7}$ & $\mathbf{8}$ & $\mathbf{9}$ & $\mathbf{1 0}$ & $k_{21}$ & $k_{22}$ & $q_{2}$ \\
\hline DEP & 19508 & 21529 & 23212 & 23465 & $\mathbf{2 3 5 2 1}$ & 23448 & 23295 & 23096 & 22875 & 22648 & $k_{21}=80$ & $k_{22}=0$ & $q_{2}=1$ \\
\hline DEP & 24117 & 27167 & $\mathbf{2 8 0 9 0}$ & 26984 & 25887 & 24929 & 24127 & 23465 & 22922 & 22477 & $k_{21}=0$ & $k_{21}=80$ & $q_{2}=0.4$ \\
\hline DEP & 21292 & 24607 & $\mathbf{2 6 7 3 3}$ & 26732 & 26332 & 25754 & 25123 & 24507 & 23937 & 23429 & $k_{21}=0$ & $k_{21}=80$ & $q_{2}=0.8$ \\
\hline DEP & 24112 & 27162 & $\mathbf{2 8 0 8 6}$ & 26980 & 25883 & 24926 & 24124 & 23462 & 22919 & 22475 & $k_{21}=10$ & $k_{21}=70$ & $q_{2}=0.4$ \\
\hline DEP & 21290 & 24606 & $\mathbf{2 6 7 3 2}$ & 26731 & 26331 & 25753 & 25122 & 24506 & 23936 & 23428 & $k_{21}=10$ & $k_{21}=70$ & $q_{2}=0.8$ \\
\hline
\end{tabular}

Further comparing the subscription pricing with the pay-per-use pricing strategy and twopart tariff pricing strategy, we can see the optimal time of two types of knowledge transactions changes from $T=5$ to $T=3$ (Table 3 and Fig. 4). The experimental results also indicate that the lower the usage rate of the proprietary big data knowledge in pricing strategies of payper-use and two-part tariff pricing, the lower the cost and higher profits in the earlier time period, but the potential profitability brought by the lower usage rate of proprietary big data knowledge is insufficient. We deem the reason for this finding could be ascribed to the fact that the amount of effective knowledge is relatively less. Still, the new proprietary big data knowledge could bring higher economic benefits for the knowledge purchaser in the short term. Meanwhile, the contracts of licensing transactions with cheaper proprietary big data knowledge are easy to be negotiated.

\subsubsection{Simulation with pricing strategies of two types of knowledge}

The purpose of knowledge providers choosing a two-part tariff pricing strategy is to obtain more consumer surplus, so the two-part tariff pricing strategy is widely used in private patent knowledge pricing and proprietary big data knowledge pricing $[17,23]$. The simulation results in Table 2 and Fig. 3 show the total DEPs when $k_{11}=50$ and $k_{12}=0.5$ are almost the same as those in lump-sum pricing scheme when $k_{12}=300$ and $k_{12}=0$, and the pricing strategy of private patent knowledge is two-part tariff pricing when $k_{11}=50$ and $k_{12}=0.5$. The pricing strategy of proprietary big data knowledge is also two-part tariff pricing when $k_{21}=10, k_{22}=70$, and $q_{2}=0.8$. If the contribution weights of private patent knowledge and proprietary big data knowledge are changed from $\omega_{1}=0, \omega_{2}=1$ to $\omega_{1}=1, \omega_{2}=0$, then simulation results in Fig. 5 show that large total DEPs are more likely to gain when the contribution weight of private patent knowledge is bigger. The reason is that the royalty payment will increase with the production of new products. The bigger the weight of private patent knowledge, the more royalty payment the knowledge purchaser has to pay. As in Fig. 5 , we can find that the time that is optimal to take knowledge transaction varies from $T=3$ to $T=7$. The experimental results show that as the weight of private patent knowledge increases, the optimal time of knowledge transaction delays. The reason is that the pricing strategy of private patent knowledge includes royalty payment related to the production of the new product. Knowledge purchaser would conduct knowledge transactions more carefully, and the negotiation of private patent knowledge transaction contracts will take longer [31]. When knowledge transaction includes only one type of private patent knowledge using twopart tariff pricing strategy, that is, the contribution weight of proprietary big data knowledge is zero, the optimal time for knowledge is the latest. Since the negotiation of private patent 
knowledge is more complicated, and a lower weight of private patent knowledge renders the immediate knowledge transaction of a more efficient knowledge. Moreover, when the knowledge transaction contains only one type of proprietary big data knowledge, a knowledge purchaser shall conduct knowledge transactions immediately when it finds that its market share begins to decline.

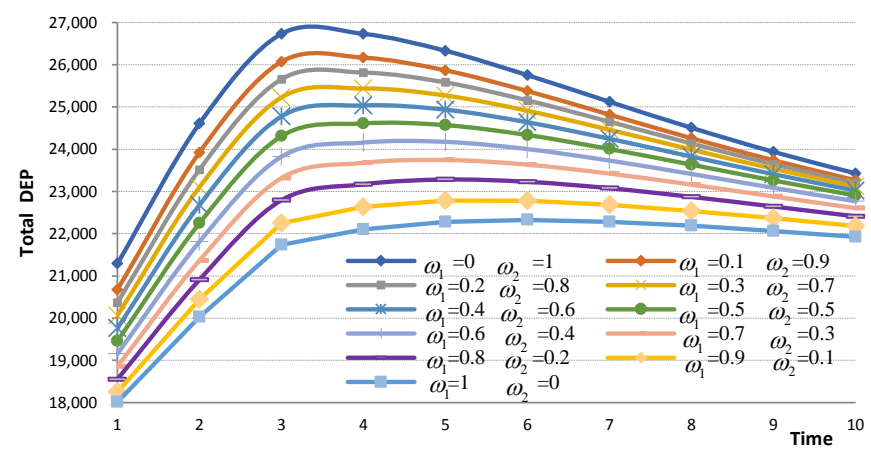

Fig. 5. Total DEPs in different weights of two types of knowledge.

According to the simulation results in Fig. 5, the model in this research no longer regards the prices of private patent knowledge and proprietary big data knowledge as constants. It is a more generalized model for the selection of knowledge pricing strategies, including two types of knowledge transactions and three types of pricing strategies. Therefore, using this model, knowledge purchasers can predict their profitability of knowledge transactions, and assist in choosing the appropriate knowledge structure, pricing strategy, and knowledge transaction time. In addition, it can help knowledge purchasers to negotiate with knowledge providers more effectively.

\section{Conclusions}

The economics of big data knowledge has recently attracted increasing attention from both academia and industry practitioners, which is especially fueled by the availability of vast amounts of consumer preference data and the fast advancement of cloud computing and machine learning technology. Firms nowadays require not only external private patent knowledge but also proprietary big data knowledge to support their new product development and survive in the hyper-competitive market. This study extends the pricing model on knowledge transaction by distinguishing between private patent knowledge and proprietary big data knowledge from knowledge transaction recipient' perspective so that they could estimate their profitability through private patent knowledge and proprietary big data knowledge transactions and facilitate these knowledge transactions more effectively. More specifically, the model can help knowledge transaction recipients to choose the optimal knowledge structure and pricing strategies for two types of knowledge, and provide theoretical and methodological guidance for knowledge recipients to negotiate with knowledge providers.

However, due to the complexity of the knowledge pricing strategies, this paper's model is plausible with some limitations. First, the transactions of private patent knowledge and proprietary big data knowledge transactions are assumed to happen simultaneously in this research. However, different types of knowledge often come from different knowledge 
providers, and they usually don't take place at the same time. Hence, future research of knowledge transactions occurring at various time points is merited. Second, the knowledge required for new product development requires more than just one type of private patent knowledge and one type of proprietary big data knowledge. Therefore, the pricing strategy of multiple knowledge will be an important research avenue for further research. In addition, different types of knowledge for one product are usually not independent. The relationships and strategic interactions of multiple knowledge transactions on the efficiency of new product development performance can be enriched in future research.

\section{Acknowledgement}

This research was supported by the National Natural Science Foundation of China, grant number 71704016, the Key Scientific Research Fund of Hunan Provincial Education Department of China, grant number 19A006, and the Enterprise Strategic Management and Investment Decision Research Base of Hunan Province (19qyzd03).

\section{References}

[1] F. Xhafa, "Advanced knowledge discovery techniques from Big Data and Cloud Computing," Enterprise Information Systems, vol. 10, no. 9, pp. 945-946, Sep. 2016. Article (CrossRef Link)

[2] X. Jiang, M. Coffee, A. Bari, J. Wang, X. Jiang et al., "Towards an artificial intelligence framework for data-driven prediction of coronavirus clinical severity," Computers, Materials \& Continua, vol. 63, no. 1, pp. 537-551, Mar. 2020. Article (CrossRef Link)

[3] G. Sun, H. Lv, D. Wang, X. Fan and Y. Zuo, "Visualization analysis for business performance of Chinese listed companies based on Gephi,” Computers, Materials \& Continua, vol. 63, no. 2, pp. 959-977, 2020. Article (CrossRef Link)

[4] I. M. Almanjahie, Z. C. Elmezouar and A. Laksaci, "Functional causality between oil prices and gdp based on big data," Computers, Materials \& Continua, vol. 63, no. 2, pp. 593-604, May 2020. Article (CrossRef Link)

[5] Y. Xue, Q. Li and F. Ling, "Teensensor: gaussian processes for micro-blog based teen's acute and chronic stress detection,” Comput Syst Sci \& Eng, vol. 34, no.3, pp. 151-164, May 2019.

[6] B. Janakiraman and S. Arumugam, "Personalized nutrition recommendation for diabetic patients using optimization techniques," Intelligent Automation \& Soft Computing, vol. 26, no.2, pp. 269280, Jan. 2020.

[7] F. Bingxu, "Design and analysis of a rural accurate poverty alleviation platform based on big data," Intelligent Automation \& Soft Computing, vol. 26, no.3, pp. 549-555, 2020. Article (CrossRef Link)

[8] Y. Xue, Q. Li, T. Wu, L. Feng, L. Zhao, and F. Yu, "Incorporating stress status in suicide detection through microblog,” Comput Syst Sci and Eng, vol. 34, no.2, pp. 65-78, Mar. 2019.

[9] M. D. Assunção, R. N. Calheiros, S. Bianchi, M. A. S. Netto, and R. Buyyaet, "Big Data computing and clouds: Trends and future directions,” J. Parallel Distrib Comput, vol. 78-80, pp. 3-15, May 2015. Article (CrossRef Link)

[10] C. Wu, Y. Chen and F. Li, "Decision model of knowledge transfer in big data environment," China Communications, vol.13, no.7, pp. 100-107, Jul. 2016. Article (CrossRef Link)

[11] C. Wu, V. Lee, and M. E. McMurtrey, "Knowledge composition and its influence on new product development performance in the big data environment," Computers, Materials \& Continua, vol. 60, no. 1, pp. 365-378, Jan. 2019. Article (CrossRef Link)

[12] E. Chantrel, A. Grimaud, and F. Tournemaine, "Pricing knowledge and funding research of new technology sectors in a growth model," Journal of Public Economic Theory, vol. 14, no. 3, pp. 493-520, Jan. 2012. Article (CrossRef Link) 
[13] F. Liu, Z. Zhang, L. Zhao, X. Zhou, and M. Xiang, "Multi-stage game of knowledge pricing," Open Automation \& Control Systems Journal, vol. 7, no. 1, pp. 421-425, May 2015. Article (CrossRef Link)

[14] E. Henry and C. J. Ponce, "Waiting to imitate: on the dynamic pricing of knowledge," Journal of Political Economy, vol. 119, no. 5, pp. 959-981, Oct. 2011. Article (CrossRef Link)

[15] K. J. Arrow, "Economic welfare and the allocation of resources for invention," Readings in Industrial Economics, pp 219-236, 1972. Article (CrossRef Link)

[16] S. Vishwasrao, "Royalties vs. fees: How do firms pay for foreign technology?," International Journal of Industrial Organization, vol. 25, no. 4, pp. 741-759, Aug. 2007. Article (CrossRef Link)

[17] M. S. Martín and A. I. Saracho, “Optimal two-part tariff licensing mechanisms,” The Manchester School, vol. 83, no. 3, pp. 288-306, jun. 2015. Article (CrossRef Link)

[18] D. Sen and Y. Tauman, "General licensing schemes for a cost-reducing innovation," Games \& Economic Behavior, vol. 59, no. 1, pp. 163-186, Apr. 2007. Article (CrossRef Link)

[19] A. K. Edinat, "Cloud computing pricing models: a survey,” International Journal of Scientific and Engineering Research, vol. 6, no. 9, pp. 22-26, Oct. 2019. Article (CrossRef Link)

[20] N. Dimitri, "Pricing cloud IaaS computing services," Journal of Cloud Computing: Advances, Systems and Applications, vol. 9, no. 1, pp. 1-11, Mar. 2020. Article (CrossRef Link)

[21] J. Huang, R. J. Kauffman, and D. Ma, "Pricing strategy for cloud computing: A damaged services perspective,” Decision Support Systems, vol. 78, pp. 80-92, Oct. 2015. Article (CrossRef Link)

[22] S. H. Chun, B. S. Choi, Y. W. Ko, and S. H. Hwang, "The comparison of pricing schemes for cloud services,” Lecture Notes in Electrical Engineering, vol. 301, pp. 853-861, 2014.

[23] S. H. Chun, "Cloud services and pricing strategies for sustainable business models: analytical and numerical approaches,” Sustainability, vol. 12, no. 1, pp. 1-15, 2020. Article (CrossRef Link)

[24] C. Wu, H. Yin, X. Yang, Z. Lu, and M. E. McMurtrey, "Pricing method for big data knowledge based on a two-part tariff pricing scheme,” Intelligent Automation \& Soft Computing, vol. 26, no. 5, pp. 1173-1184, 2020. Article (CrossRef Link).

[25] M. Reisinger, “Two-part tariff competition between two-sided platforms,” European Economic Review, vol. 68, no. 3, pp. 168-180, May 2014. Article (CrossRef Link)

[26] D. Teece, “Technology transfer by multinational firms: the resource cost of transferring technological know-how,” The Economic Journal, vol. 87, no. 346, pp. 242-261, 1977. Article (CrossRef Link)

[27] C. Wu and D. Zeng, "Knowledge transfer optimization simulation for innovation networks," Information Technology Journal, vol. 8, no. 4, pp. 548-594, Apr. 2009. Article (CrossRef Link)

[28] Y. H. Farzin, K. Huisman and P. Kort, “Optimal timing of technology adoption,” Journal of Economic Dynamics and Control, vol. 22, no. 5, pp. 779-799, May 1998. Article (CrossRef Link)

[29] U. Doraszelski, "Innovations, improvements, and the optimal adoption of new technologies," Journal of Economic Dynamics and Control, vol. 28, no. 7, pp. 1461-1480, Apr. 2004. Article (CrossRef Link)

[30] C. Wu, E. Zapevalova, Y. Chen, and F. Li, “Time optimization of multiple knowledge transfers in the big data environment,” Computers Materials \& Continua, vol. 54, no. 3, pp. 269-285, Mar. 2018. Article (CrossRef Link)

[31] K. C. A. Wang, W. J. Liang, and P. S. Chou, "Patent licensing under cost asymmetry among firms," Economic Modelling, vol. 31, pp. 297-307, Mar. 2013. Article (CrossRef Link) 


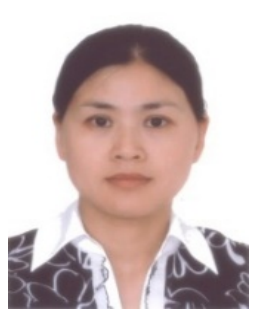

Chuanrong Wu received $\mathrm{PhD}$ in Business Administration from Hunan University, China, in 2009. She is currently an associate professor in College of Economy and Management, Changsha University of Science \& Technology. Her research interests include big data management, knowledge management, technology innovation management and computational experiments.

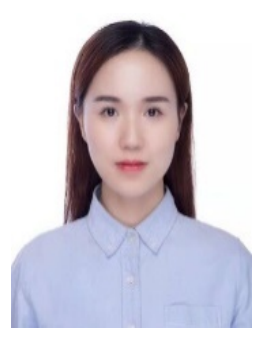

Ning Tan received the B.S degree in mechanics and electronics from Shanghai Dianji University, Shanghai, China, in 2011. She worked as a cabin crew for Emirates Airline from 2012-2016. She is now pursuing the Master of Public Administration in Economics and Management Department, Changsha University of Science \& Technology, Hunan, China. Her current research interests include strategic management and public policy research.

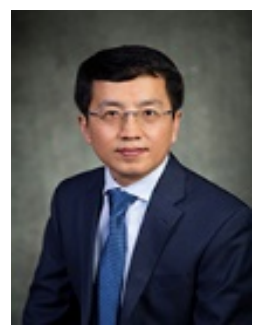

Zhi Lu received his Ph.D. in Business Administration from the Pennsylvania State University in 2016. He is currently an Assistant Professor of Marketing and Innovation at the Peter B. Gustavson School of Business at the University of Victoria. His scholarly research interests: service marketing, innovation and entrepreneurship, and sustainability, with special interests in Artificial Intelligence and its application in commerce, customer experience, and disruptive technology innovation.

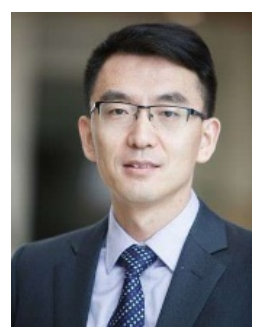

Xiaoming Yang has a Ph.D. degree in entrepreneurship and innovation from the University of Missouri-Kansas City. He is an assistant professor at the college of business administration at the University of Nebraska Omaha. His research interests include the cognitive behavior of entrepreneurs, new product development, technological entrepreneurship, and corporate entrepreneurship.

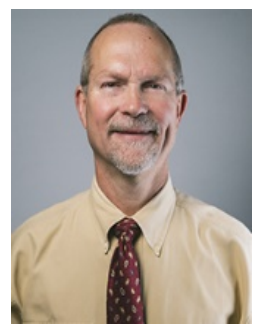

Mark E. McMurtrey has a Ph.D. degree in Management Information Systems from the University Of South Carolina in 1997. He is a professor and MBA Director at the college of business at the University of Central Arkansas. His research interests include big data management, systems engineering, information management, and strategic management. 